\title{
SOBRE EL CONTENIDO DE INJUSTO DE LA PREVARICACIÓN JUDICIAL
}

\author{
ON THE CONTENT OF WRONGFULNESS \\ OF JUDICIAL MISCONDUCT
}

\begin{abstract}
Luis EMILIO Rojas A.*
RESUMEN: Una aproximación a los tipos de prevaricación judicial exige revisar el baremo desde el cual se determina su contenido de injusto. Tradicionalmente, la cuestión se ha debatido entre la teoría objetiva y la subjetiva acerca de la prevaricación. Sin embargo, la teoría objetiva parte ingenuamente de la existencia de preceptos jurídicos inequívocos, mientras que la subjetiva supone que se llega al derecho mediante la sola convicción del juez. A partir de una exploración en los elementos de una decisión judicial correcta, el trabajo plantea que la prevaricación supone una decisión judicial insostenible que a su vez conlleva una subsunción incorrecta.
\end{abstract}

Palabras clave: Prevaricación, decisión judicial, corrección, insostenibilidad.

ABSTRACT: An approximation to the crimes of judicial misconduct requires reviewing the scale from which illicitness is determined. Traditionally, the question has been debated between objective and subjective theory of misconduct. While the objective theory naively starts from the existence of unequivocal legal precepts, the subjective theory supposes that the law is established through the sole conviction of the judge. Based on an exploration of the elements of a correct judicial decision, the work proposes that misconduct supposes an unjustifiable judicial decision that in turn entails an incorrect subsumption.

Keywords: Judicial misconduct, judicial decision, correction, unjustifiable decision.

\section{SOBRE LA POSIBILIDAD DE LA PREVARICACIÓN JUDICIAL}

El contexto de surgimiento de las diversas normas sobre prevaricación judicial se encuentra marcado por la pretensión ínsita a un Estado de Derecho en orden a someter la función judicial a límites estrictos. En nuestra tradición jurídica, tal intención se plasma ya en el texto de la Constitución de 1822 mediante la consagración del principio de responsabilidad de los jueces - art. 201 y art. 205, principio que alcanza una formulación sintética en el art. 111 de la carta fundamental de $1833^{1}$ y cuyo tenor se mantiene casi idéntico en

* LL.M. y Doctor por la Albert-Ludwigs-Universität Freiburg. Profesor de Derecho Penal en la Universidad Alberto Hurtado. El presente trabajo se enmarca en el proyecto Fondecyt regular N. 1180596, cuyo investigador responsable es el autor y quien agradece la imprescindible colaboración brindada por el Mg. Claudio Quintana y el licenciado Juan Ignacio Cuitińo; asimismo, el autor agradece las observaciones críticas formuladas al borrador del presente trabajo por los profesores Dra. Flavia Carbonell y Dr. Héctor Hernández con motivo de un workshop sobre "decisión judicial y error" desarrollado en septiembre 2020.

1 Art. 111. Los jueces son personalmente responsables por los crímenes de cohecho, falta de observancia de las leyes que reglan el proceso, i en jeneral por toda prevaricación o torcida administración de justicia. La lei determinará los casos i el modo de hacer efectiva esta responsabilidad. 
las constituciones del siglo 20. Ese ímpetu puede explicar la regulación extremadamente casuística de la prevaricación en los artículos 223, 224 y 225 del Código Penal (CP) con la tipificación, en esa época, de nada menos que quince hipótesis repartidas en los diversos numerales de estos preceptos ${ }^{2}$. Cada una de ellas parece responder a la voluntad del legislador de someter al juez a uno u otro principio básico de la jurisdicción, como el de legalidad, probidad o jerarquía ${ }^{3}$. En medio de la siempre pujante demarcación entre legislación y jurisdicción, las normas sobre prevaricación judicial propia aspiran a cumplir una función peculiar. Se trata del art. 223 N. 1, del art. 224 N. 1 y N. 2 y del art. 225 N. 1 y N. 2 CP $^{4}$. El texto de estas disposiciones pareciera expresar la doble intención del legislador en orden a sujetar al juez a las normas de derecho material extraídas a su vez de preceptos legales en el momento de fallar una causa civil o criminal - "ley expresa y vigente"- y, con antelación a ello, a las "leyes que reglan la substanciación de los juicios" civiles o penales, esto es, las normas de derecho formal. En clave de los principios rectores de la jurisdicción, tales normas suponen la voluntad de someter al juez al principio de legalidad, incluida la legalidad del proceso $^{5}$. O, recurriendo a una expresión más plástica de Binding sobre la tarea propia del juez, parten de la premisa de que la legalidad es "su única profesión".

Esa pretensión del legislador, empero, supone una determinada visión acerca de la función jurisdiccional. Los tipos de prevaricación aparecen construidos sobre la base de lo que puede llamarse un "paradigma clásico de decisión judicial" acota la tarea jurisdiccional a la función de aplicar el derecho vigente en un caso concreto ${ }^{8}$. Desde el punto de vista del razonamiento judicial, ese modelo se estructura en la forma del silogismo cuyo núcleo es la operación de subsunción del hecho comprobado bajo el supuesto descrito de modo abstracto por la norma general ${ }^{9}$. Sin embargo, esa concepción, tan antigua como el derecho moderno y después reforzada por el más puro positivismo jurídi$\mathrm{Co}^{10}$, se ha resquebrajado por tendencias desarrolladas simultáneamente a lo largo del siglo 20 tanto en el plano de la legislación como en el de la jurisdicción. En el suelo de la tradición jurídica continental, la legislación contemporánea ha tendido a abandonar el marco sistemático de la codificación para empezar a articularse en la forma de "leyes de medidas"

\footnotetext{
${ }^{2}$ Originalmente ubicado en el título sobre "delitos que afectan los derechos garantidos por la Constitución" y después trasladado bajo el título "de los delitos cometidos por empleados públicos en el desempeño de sus cargos", el párrafo dedicado a la prevaricación fue objeto de discusión en las sesiones 35 de 5.5.1871, 49 de 21.7.1871, 150 de 6.06.1873 y 152 de 10.06.1873, de la Comisión Redactora del Código Penal Chileno (1873).

3 Véase la notable y todavía vigente exposición de Acosta (1983) pp. 105 y ss.

${ }^{4}$ Por todos, Ossandón y Rodríguez (2008) pp. 192 y ss., 208 y ss.; no obstante, estos autores desglosan los tipos del art. 224 N. 2 y del art. 225 N. 2 de la prevaricación judicial propia.

5 En este sentido, Acosta (1983) pp. 115 y ss.

${ }^{6}$ Binding (1905) t. 2, p. 554, invocando el art. 150 de la Carolina: se encuentra obligado (bei seinem eydt und seiner seel seligkeyt schuldig) a juzgar según su mejor comprensión con igualdad y justicia.

7 Caracciolo (2011) pp. 2 y ss., en contraste con varios "paradigmas discrecionales".

8 En tanto los programas del derecho son siempre condicionales y jamás finales, LuHMANN (1993) pp. 195 y ss., pp. 187 y ss.

9 Un formidable estudio de este modelo ofrece ENGISCH (1960) pp. 22 y ss.; después Larenz y Canaris (1995) pp. 91 y ss.; muy claro Weinberger (1988) pp. 187 y ss.

10 Haverkate (1977) pp. 40 y ss.
} 
y de "regulaciones orientadas a un fin" ${ }^{11}$. Y, paralelamente, en el plano de la jurisdicción la autocomprensión del juez se ha visto significativamente transformada a más tardar desde la época de la segunda postguerra ${ }^{12}$. Fue Josef Esser quien ya en 1970 hizo ver con mucha claridad que la decisión judicial no resulta meramente de una operación lógica, sino que se encuentra guiada por la precomprensión del juez acerca tanto de la premisa mayor como de la premisa menor. Según Esser, el juez busca la regla de derecho desde la confrontación actual con el caso, aproximación que le exige adelantar un juicio de valor tanto acerca de la adecuación de la consecuencia jurídica como de la solución justa del conflicto. Por su lado, la premisa menor no radica simplemente en un hecho, sino que se define por las expectativas de solución justa colocadas por las partes en el proceso. La decisión judicial, entonces, se funda en lo que ese inmenso jurista llama un proceso de "subsunción final", en el sentido de que el juez realiza la operación de subsunción orientado teleológicamente por su propia precomprensión y valoración previa del caso ${ }^{13}$.

En este contexto de doble transformación en la comprensión tanto de la ley como de la propia jurisdicción, surge la pregunta por la posibilidad misma de la prevaricación judicial. Puesto que si, por un lado, estos tipos presuponen la vinculación del juez al derecho y, por el otro, la prevaricación se define por una decisión judicial que contraviene el derecho, entonces la posibilidad de realización de lo injusto de este delito dependerá tanto de la comprensión que se tenga previamente acerca de la norma jurídica como del modo en que se conciba la actividad de aplicarla en un caso concreto, es decir, del paradigma de decisión judicial. La forma en que este paradigma impregna la visión que se tiene de este delito se ve reflejada en la clásica disputa entre teoría objetiva y subjetiva de la prevaricación ${ }^{14}$. Según la teoría objetiva, lo injusto de la prevaricación surge de una decisión acerca de la consecuencia jurídica que contraviene el derecho objetivo, esto es, que declara la existencia o impone una consecuencia no prevista por la norma o, a la inversa, que no reconoce o niega la existencia de una consecuencia establecida en ella. Supone como baremo la existencia de algo así como un "derecho contenido en un precepto" y pone el acento en la conclusión de la decisión judicial ${ }^{15}$. En cambio, la teoría subjetiva parte de la premisa de que la existencia o no de un derecho subjetivo depende de la convicción del propio juez al respecto, de modo que la prevaricación concurre debido a que "el juez no reconoce arbitrariamente un derecho subjetivo de cuya existencia se encuentra convencido o, al revés, arbitrariamente declara como dado un derecho subjetivo respecto del cual sabe que no existe" ${ }^{16}$. Se tilda de subjetiva esta teoría porque, como puede verse, fija como parámetro desde el cual se deter-

\footnotetext{
11 Sobre la racionalidad de la "comprensión de la ley" EsSER (1972) pp. 83 y ss.; en nuestro contexto, una manifestación grotesca de esa tendencia se ha plasmado en las recientes "leyes con nombres".

12 Sobre la racionalidad y responsabilidad del juez Esser (1972) pp. 116 y ss.

13 Esser (1972) pp. 30 y ss., 48 y ss., 68 y ss., 76 y ss. (p. 80: "la lógica es presupuesto, pero no fundamento del conocimiento. Ella no puede garantizar la decisión acerca de la elección de la norma y su rol determinante para la solución del conflicto”), 106 y ss., 121.

14 Véase la exposición de OSSANDón y Rodríguez (2008) p. 194 y s.

15 Hilgendorf (2009) núm. marg. 47 y ss.

16 Kohler (1904) p. 614 y s.
} 
mina lo injusto de la prevaricación a la propia convicción del juez acerca de la existencia de un derecho y no a la norma jurídica misma ${ }^{17}$.

La teoría objetiva parte ingenuamente del supuesto de la presencia de un "derecho objetivo", contenido en un precepto legal y dado previamente al juez ${ }^{18}$. Por su lado, la teoría subjetiva acierta en sostener que la existencia o no de un derecho supone la declaración de un juez, pero incurre en un exceso al hacerla derivar de su pura convicción. En esta disputa se trasluce la paradoja que plantea la prevaricación judicial, pues esta supone la existencia de algún baremo externo al juez a partir del cual se pueda juzgar la incorrección de su decisión, mas al mismo tiempo dicho baremo se configura mediante la actividad del propio juez en tanto co-creador del derecho. El propio Binding cayó en una aporía al sostener, por un lado, que "la jurisdicción es la tarea específica del juez" y "si esta es justa pero su fundamentación conscientemente incorrecta, no hay prevaricación”, para enseguida asentar la idea de que "la decisión prevaricadora contraviene necesariamente la ley"19. Y, por el otro, al plantear en el caso de que el juez tuviese dudas sobre la interpretación de la ley pertinente o su vigencia, sin llegar a una convicción firme, que este no cometía prevaricación de subordinarse a una concepción "según su opinión" superior, fuera la autoridad de un sabio o de un tribunal supremo, y de ser incluso esta incorrecta a juicio del juez, este debía atenerse a su propia convicción, pues: "para cada juez es ley solo su interpretación de la ley y él debe juzgar, no un tercero a través suyo" ${ }^{20}$. El intento de disolver esta aporía constituye el punto de partida de la tesis formulada en 1970 por Hans-Joachim Rudolphi, despectivamente calificada por la doctrina alemana como una mera teoría de la "infracción de deber" ${ }^{21}$. Partiendo de una tesis objetiva, Rudolphi hacía ver que el límite de esta radica en que supone un "norma jurídica clara e inequívoca" para luego plantear, extendiendo el alcance del tipo a partir de su fin de protección, la posibilidad de la prevaricación también en los supuestos en que la ley usa conceptos ambiguos o requeridos de valoración o que abren espacios de discrecionalidad, en la medida en que el juez contraviniese la "norma de decisión" que surgiera de la aplicación correcta de los "medios y métodos de interpretación científico-jurídica" 22 . Esta tesis tiene el gran mérito de mostrar que lo injusto de la prevaricación no se reduce a una conclusión de la decisión contraria a derecho, sino que ya surge de la forma incorrecta de llegar a ella, por ende, de una fundamentación incorrecta. Siempre en la intención de disolver la aporía reseñada, enseguida se propone una reformulación de esta tesis en el sentido de que el contenido de injusto de la prevaricación radica en una subsunción incorrecta condicionada por una acción del juez de fundar la decisión con in-

\footnotetext{
17 Es posible observar una conexión entre esta teoría y el “movimiento del derecho libre”, HaVERKATE (1977) p. 120 y s., respecto de esta escuela.

18 Certera crítica de Müller y Christensen (2013) t. 1, pp. 223 y ss., pues el precepto no contiene ni porta la norma, sino que esta surge recién de la atribución de significado por el juez en el caso concreto, usando la regla (invocando los "juegos de lenguaje" y la "forma de vida" en Wittgenstein).

19 Binding (1905) t. 2, p. 558 y s.

20 Binding (1905) t. 2, p. 560.

21 Una valoración equilibrada de la discusión en BACigalupo (2004) pp. 385 y ss.

22 Rudolphi (1970) pp. 610 y ss.
} 
fracción de las reglas de interpretación y los estándares de argumentación propios de una tradición jurídica determinada.

\section{JUSTIFICACIÓN DE LAS NORMAS SOBRE PREVARICACIÓN JUDICIAL: UNA CONSIDERACIÓN DE TEORÍA DE LAS NORMAS PARA PRECISAR EL BIEN JURÍDICO PROTEGIDO}

El análisis del contenido de injusto descrito por cualquier tipo penal supone antes considerar las razones que justifican su existencia en un ordenamiento jurídico, es decir, su legitimación. Este ejercicio previo se traduce usualmente en la identificación del bien jurídico protegido por su respectiva norma de comportamiento, que en el caso de este conjunto de normas reconocidamente es la "administración de justicia"23.

Desde ese punto de vista, empero, los tipos de prevaricación son doblemente peculiares. En primer lugar, porque comparten el sentido que tienen todas aquellas normas cuyo objeto radica en proteger el funcionamiento correcto del sistema de justicia, sistema cuya función, a su vez, consiste en asegurar la vigencia práctica de las normas jurídicas que pretenden regular la vida en sociedad y que, de no operar, correrían el riesgo de quedarse en meras declaraciones ${ }^{24}$. Se sostiene lo mismo, aunque en un lenguaje más sociológico, cuando se afirma que la función de tales normas radica en asegurar el imperio o "dominio del derecho" en una sociedad determinada ${ }^{25}$. Las normas aquí en cuestión, sin embargo, también son jurídicas, de modo que surge la pregunta por la relación funcional entre normas que pertenecen al mismo ordenamiento jurídico. Pues bien, las normas que confieren "potestades judiciales" y así regulan la "administración de justicia" son accesorias en relación con otras normas que sirven a su turno como pautas o criterios de comportamiento para los ciudadanos y brindan así protección a los más diversos intereses ${ }^{26}$. En este sentido, Bierling había ofrecido ya a fines del siglo 19 una clasificación de las normas jurídicas según su "valor práctico", valor que a su vez depende del fin perseguido por cada clase de ellas. Así, las normas primarias buscan regular la vida en comunidad, mientras que las secundarias se definen por cumplir una función auxiliar para el caso del fracaso o insuficiencia de aquellas; en palabras de Bierling, son "normas hipotéticas cuya condición, única bajo la cual adquieren relevancia, es el fracaso o insuficiencia de una norma primaria" ${ }^{27}$. Entre las normas secundarias se incluyen todas aquellas que sirven para contrarrestar el injusto o conservar la vigencia de las normas primarias como tales frente a su infractor, las que contemplan una reparación por el daño a un interés material, pero también las normas procesales cuyo fin radica en la "producción de una decisión superior o imposición sobre el sentido y la

${ }^{23}$ Acosta (1983) p. 110 y s.; crítica al concepto de "administración de justicia" en GuZmán Dalbora (2008) pp. 20 y ss.

24 Wilendann (2011) pp. 537 y ss.

25 Así, entre otros, Rudolphi (1970) pp. 627 y ss.

${ }^{26}$ HaRT (2012) pp. 33 y ss. (“diversidad de normas jurídicas"), p. 49 y s. (accesorias en relación con las reglas que cumplen una función primaria), p. 101 (reglas de tipo primario y reglas de tipo secundario), pp. 113 y ss.

27 Bierling (1894) t. 1, pp. 108, 133 y ss., 135. 
aplicación de las normas jurídicas primarias en el caso concreto" ${ }^{28}$. Pues bien, en la medida en que las normas de sanción contempladas para la prevaricación a su vez tienen como supuesto el "fracaso o insuficiencia" de alguna norma secundaria, los tipos correspondientes cumplen una función auxiliar en relación con esta segunda clase de normas, es decir, su fin y sentido radica en asegurar la vigencia de las normas secundarias e indirectamente de las primarias; en breve, se trata de normas terciarias.

En segundo lugar, y siempre al interior de ese plexo de normas, los tipos de prevaricación evidencian una peculiaridad adicional que los vuelven incluso únicos. Esta radica en que el destinatario de estas normas de comportamiento es el propio juez, cuya posición en el ordenamiento jurídico es desde luego muy diversa a la de los ciudadanos o de las partes del proceso, pero también diferente a la de otros funcionarios que intervienen en este. El proceso es el espacio contemplado por el Estado para el reconocimiento de los derechos subjetivos y en su interior este le confiere al juez la tarea fundamental de adoptar una decisión acerca de la existencia o no de las pretensiones jurídicas canalizadas por esa vía ${ }^{29}$. La posición que ocupa este sujeto es única, en tanto funge como intermediario autoritativo entre la ley y "aquellos que quieren o deben escuchar la voz viva de ella acerca de la existencia de sus derechos o deberes en el caso concreto" ${ }^{30}$. En un sentido práctico, el juez se ubica, en el caso concreto, sobre la ley al determinar su contenido y el alcance de las expresiones particulares de manera definitiva mediante la interpretación que les propia. Como dice Binding: "en esa posición, nadie se le equipara en el Estado, ni siquiera el rey, mientras este no sea juez" ${ }^{31}$. Dicho lo anterior con otras palabras, el ordenamiento jurídico se expresa a través del juez, es decir, y como lo plantea el propio Kelsen, este crea derecho ${ }^{32}$.

En la distribución de las tareas estatales, el juez cumple la función jurisdiccional asignada al tribunal en un Estado de Derecho. Tal función se traduce en la solución de los conflictos de intereses mediante la sentencia judicial cuyo contenido radica en la clasificación de un caso individual bajo uno genérico acerca de la cual existe una controversia o en la calificación normativa de un determinado comportamiento siempre controvertida ${ }^{33}$. En este sentido, es posible concretar el bien jurídico postulado en los términos de la "administración de justicia” y precisarlo para así colegir que lo protegido por las normas de compor-

\footnotetext{
28 BierLing (1894) t. 1, p. 137.

29 Binding (1905) t. 2, pp. 514 y ss.

BINDING (1905) t. 2, p. 553.

BINDING (1905) t. 2, p. 553 y s.

32 Kelsen (1960) p. 419 y s., aunque en una formulación algo enrevesada: "una norma que determina la creación de otra norma se aplica en la creación determinada por aquella de la otra norma. Aplicación del derecho es al mismo tiempo creación del derecho" (página original: 240); críticos Alchourrón y Bulygin (2015) p. 217 nota 17.

33 Alchourrón y Bulygin (2015) pp. 204 y ss., distinguiendo luego entre sentencias declarativas, que contienen una proposición sobre la clasificación de un caso individual bajo el genérico y cuyo efecto normativo es solo secundario porque se encuentra asignado por otra norma, y sentencias normativas, que contienen una norma reguladora del caso individual y cuyo efecto normativo es primario.
} 
tamiento subyacentes a los tipos de prevaricación judicial consiste en el ejercicio correcto de la jurisdicción en un Estado de Derecho ${ }^{34}$.

Ahora bien, la función jurisdiccional, a su vez, se protege solo fragmentariamente por las diversas normas sobre prevaricación. Entre los diversos presupuestos del ejercicio correcto de la jurisdicción, es preciso identificar el principio básico que subyace en particular a los tipos de prevaricación judicial propia. La misma pregunta surge si se parte de la tesis de que el bien jurídico protegido es simplemente la "administración de justicia”, pues entonces resulta igualmente necesario concretarlo recurriendo también a los principios y deberes básicos a los cuales dicha función se encuentra sometida a fin de diferenciar entre "correcta e incorrecta administración de justicia”, máxime si se trata como aquí nada menos que del propio juez ${ }^{35}$. Pues bien, y como ya se ha adelantado, los tipos del art. 223 N. 1, del art. 224 N. 1 y del art. 225 N. 1 CP se colocan en el momento mismo de dictación de la decisión judicial. En el camino de la jurisdicción, trazado por el propio art. 76 de la Constitución (CPR) y por el art. 1 del Código Orgánico de Tribunales (COT), dichos tipos se ubican en la fase de juicio de las causas civiles o criminales por parte de los tribunales establecidos por la ley. Así, el tipo del art. 223 N. 1 se refiere al comportamiento de fallar una causa civil o criminal "a sabiendas" contra ley expresa y vigente. Por su lado, los tipos de negligencia del art. $224 \mathrm{~N}$. 1 y del art. $225 \mathrm{~N}$.1 CP aluden a la dictación de una "sentencia manifiestamente injusta" en una causa civil o criminal. Desde el punto de vista de las acciones del juez, estos tipos se refieren a la decisión judicial que resuelve la causa civil o criminal, esto es, a una sentencia definitiva u otra resolución judicial equivalente. Pero, como se puede ver, en cuanto al baremo con el cual se compara la decisión judicial, el tipo doloso lo fija en la ley, mientras que los tipos de negligencia parecen suponer como medida al "valor de la justicia". Admitir esta dualidad del baremo de comparación, empero, implicaría que una sentencia abiertamente contraria al "principio de justicia", dictada como consecuencia de una negligencia del juez, pero cuyo tenor todavía se reconduce al texto de la ley realizaría estos tipos de negligencia, mientras que si la misma sentencia se hubiere dictado dolosamente por parte del juez no se realizaría el tipo del art. $223 \mathrm{~N}$. $1 \mathrm{CP}^{36}$. Esta disarmonía, probablemente consecuencia de la regulación casuística de la prevaricación y la disímil atención brindada por la Comisión Redactora del CP, obliga a una interpretación sistemática de estos preceptos. Es menester fijar un baremo común de comparación. En este sentido, Guzmán Dalbora propone aquí sintetizar "lo justo y lo legal" en un mismo principio: "el Derecho y su entero sistema de fuentes" ${ }^{37}$. Este planteamiento, no obstante, requiere ser precisado en el sentido de que el baremo viene dado solo por el "derecho legislado", de modo que la prevaricación supone una decisión judicial dictada en contravención al derecho fijado en la legislación. Por consiguiente, estos tipos se fundan en la vinculación del juez a las normas del derecho material en el momento de dictar la decisión que resuelve

\footnotetext{
34 En este sentido recurren también al concepto de función jurisdiccional para la justificación de estos tipos penales Guzmán Dalbora (2008) p. 21 y s.; Ossandón y Rodríguez (2008) pp. 168 y ss.

35 Así lo reconoce explícitamente Acosta (1983) pp. 111 y ss.

36 Guzmán Dalbora (2008) p. 129 y s.

37 Guzmán Dalbora (2008) p. 130.
} 
el caso, en otras palabras, al ejercer la facultad de juzgar las causas civiles o penales sometidas previamente a su conocimiento. El principio de la jurisdicción, entonces, que sirve de fundamento a estas normas es el de estricta sujeción del tribunal al derecho. Este principio, si bien no se encuentra explícitamente reconocido, surge de una interpretación sistemática del art. $76 \mathrm{CPR}$ en relación con los artículos 1 y 12 del $\mathrm{COT}^{38}$. En consecuencia, las normas de comportamiento subyacentes a estos tipos de prevaricación se justifican por el fin de asegurar la vigencia efectiva del principio de sujeción al derecho en el momento de fallar una causa civil o criminal, es decir, conectan con ese principio básico que obliga al juez a someterse al derecho en ese hito esencial del camino de la jurisdicción ${ }^{39}$.

\section{APROXIMACIÓN AL MODELO DE DECISIÓN JUDICIAL CORRECTA PARA DILUCIDAR LA ESTRUCTURA DE INJUSTO DE LA PREVARICACIÓN}

¿Qué significa dictar una decisión judicial sujeta al derecho aplicable, esto es, observando este principio básico de la jurisdicción? Esta pregunta es clave para poder delimitar el contenido de injusto de los tipos de prevaricación, pues estos comparten el núcleo de la contravención al derecho legislado. Pero, además, tal principio rige no solo respecto de los jueces de los tribunales de instancia, sino también en relación con los jueces que integran los tribunales superiores de justicia, incluida la propia Corte Suprema. De hecho, la norma del art. 223 CP se refiere en su encabezado a los jueces de los "tribunales colegiados o unipersonales" en una época en que solamente las Cortes de Apelaciones y la Corte Suprema eran tribunales colegiados, de modo que es clara la intención del legislador en orden a incluir también a los miembros de estos tribunales superiores en el círculo de autores del delito de prevaricación. Esta constatación no se ve alterada por la mera excusa legal absolutoria contemplada por la regla del art. 324 inciso 2 COT, que excluye solo la punibilidad de "los miembros de la Corte Suprema en lo relativo a la falta de observancia de las leyes que reglan el procedimiento" y la torcida administración de la justicia, esto es, precisamente en estas hipótesis de prevaricación. También una decisión emanada de una Corte de Apelaciones o de la propia Corte Suprema puede realizar el contenido de injusto de la prevaricación, solo que en el caso de los integrantes de la Excma. Corte esta resta impune. Es preciso, entonces, delimitar el injusto propio de la prevaricación en términos tales de que pueda ser realizado por cualquier juez, de un tribunal unipersonal o colegiado, de instancia o superior, en un caso civil o penal. En este sentido, el contenido de injusto de la prevaricación no puede agotarse en el error de derecho como causal del recurso de casación en el fondo -art. 767 del Código de Procedimiento Civil- o de nulidad -art. 373 b) del Código Procesal Penal. Pues, si ello fuera así, entonces solo el juez del tribunal inferior podría cometer prevaricación, mientras que el del tribunal superior llamado a corregir el error jamás podría cometerla.

\footnotetext{
38 WilenMann (2011) pp. 543 y ss., 546 y s.

39 Esta obligación forma parte del "código judicial" al cual se refiere HarT (2012) p. 37, o integra el "sistema del juez” al que se refieren Alchourrón y Bulygin (2015) pp. 211 y ss.
} 
Asumiendo que la cuestión se mueve en un plano eminentemente normativo y que ella se inserta en un "círculo hermenéutico" del cual no es posible salir, es necesario igualmente desarrollar esta tautología ${ }^{40}$. Un paso en esta dirección consiste en visualizar los extremos opuestos, esto es, de un lado, una decisión judicial -correcta- vinculada a derecho y, del otro, una incorrecta por contradecirlo abiertamente. Así podrá delimitarse el contenido de injusto de la prevaricación ubicada en este extremo.

\section{Conceptos de DeCisión JUdicial}

A fin de ver el extremo de una decisión judicial correcta, parece indicado explorar algunos modelos desarrollados por la teoría del derecho. Como punto de partida, es iluminador tener presente una distinción subrayada por Caracciolo de la decisión judicial como norma y como acto, pues, una norma particular puede derivarse de una general, pero "los actos de los jueces no se derivan de normas" ${ }^{41}$. En este sentido, la decisión como norma puede ser concebida como el resultado de una serie de actos realizados de manera concatenada por el juez. Así, en nuestro medio, Carbonell la define "como el resultado del procedimiento que lleva a cabo el juez para resolver un problema con relevancia jurídica que ha sido sometido a su conocimiento y que puede ser reconstruido a través de dos premisas y de una conclusión” ${ }^{2}$. Mas, por otra parte, según la jurista chilena "cada una de estas premisas puede ser vista como un conjunto de actividades cuyo producto, a su turno, se expresa en enunciados o en decisiones" ${ }^{\star 3}$. Otro concepto de decisión judicial es acuñado por el jurista austríaco Ota Weinberger en los siguientes términos: "la decisión jurídica es un acto jurídico individual que regula autoritativamente una relación jurídica entre sujetos determinados. Mediante una decisión jurídica se crea una norma jurídica particular fundada en una potestad dada al órgano estatal en un proceso jurídicamente regulado. La base normativa de la decisión viene dada por normas jurídicas generales que se aplican en el proceso a un hecho comprobado" 44 .

Estas definiciones pueden sintetizarse en que la decisión judicial como resultado o producto se funda en dos premisas, una normativa y otra fáctica. La premisa mayor o normativa se encuentra constituida por reglas válidas del ordenamiento jurídico que asignan consecuencias a supuestos descritos en ellas. La premisa menor o fáctica consiste en una proposición sobre el hecho jurídicamente relevante. Y la conclusión resulta de la subsunción del hecho comprobado bajo la regla interpretada dando origen así a la norma particular. Así concebida, la decisión judicial responde al esquema de la subsunción, que constituye "el esqueleto lógico del razonamiento jurídico en la búsqueda del contenido normativo de la decisión y su fundamentación” ${ }^{45}$. Pues bien, en la medida en que la de-

40 La paradoja de la jurisdicción LuHMANN (1993) pp. 320 y ss.

41 Caracciolo (2011) p. 3.

42 Carbonell (2017) p. 22.

43 Carbonell (2017) p. 23.

44 Weinberger (1988) p. 187.

45 Weinberger (1988) p. 188 y s.; Larenz y Canaris (1995) pp. 91 y ss. 
cisión se estructura de ese modo y la conclusión se infiere de las premisas aceptadas como válidas, ella se encuentra justificada internamente ${ }^{46}$.

Las premisas de la decisión, empero, han de ser válidas para que la conclusión sea correcta. Y las premisas son válidas si se encuentran justificadas externamente. Según Wróblewski, una decisión se justifica externamente "cuando sus premisas están calificadas como buenas según los estándares utilizados por quienes hacen la calificación”, esto es, "por el crítico" ${ }^{7}$. La justificación de cada premisa exige la realización por parte del juez de un conjunto de actividades cuyo resultado es una premisa normativa válida y una premisa fáctica verdadera. Luego, la operación de subsunción implica la creación de una norma jurídica particular que, por definición, es el producto de una acción del juez. Es decir, aquí la decisión judicial es vista como un conjunto de acciones del juez que funda las premisas y da lugar a la decisión como resultado. Es aquí donde se realiza el auténtico trabajo jurídico $^{48}$. Este radica en la elaboración previa de las premisas y de la norma particular, actividad cabalmente orientada por la precomprensión del juez. Según Esser, en ella el juez valora previamente la adecuación del "modelo de la regla jurídica" para la solución actual del "conflicto jurídico" surgido del hecho ventilado en el proceso ${ }^{49}$. Al realizar esta actividad, el juez asume una responsabilidad de cara a las partes y a los potenciales involucrados en la "situación de conflicto", cuyos intereses forman un "horizonte de expectativas" del cual aquel no puede escapar ${ }^{50}$.

Ciertamente que la premisa normativa no se descubre ni se encuentra, sino que más bien el juez la selecciona en un proceso íntegramente orientado por su precomprensión del caso. Tampoco la premisa fáctica se reduce a un "hecho desnudo", sino que surge de un proceso de pregunta previa, valoración probatoria y decisión conducido por el juez ${ }^{51}$. Y desde luego que la norma particular, como bien dice Esser, "no se encuentra dada, sino que entregada" al juez ${ }^{52}$. Es este sujeto el que crea o construye la norma jurídica particular en el caso concreto ${ }^{53}$. Por ende, la acción de aplicación del derecho en un caso concreto no se reduce a una operación lógica de subsunción. En definitiva, consiste en una decisión del juez. Pero esta decisión no es libre, pues cada una de las actividades previas se encuentra sometida a límites, reglas y estándares propios de una tradición jurídica determinada.

\footnotetext{
46 WróbleWSKI (2013) p. 52 y p. 61.

47 WróblewsKi (2013) p. 52 y p. 61.

48 Müller y Christensen (2013) pp. 207 y ss., 275 y ss.

49 Esser (1972) pp. 31 y s., 41 y s., 43 y ss., 48 y ss., 54.

50 EsSER (1972) pp. 68 y ss., p. 77 (no se trata entonces de una técnica, por lo que tampoco corresponde hablar aquí de lex artis), pp. 136 y ss.

51 Confrontar con Coloma (2017) pp. 86 y ss.

52 ESSER (1972) p. 135.

53 Incluso Müller y Christensen (2013) pp. 235 y ss., llegan a sostener que produce la norma jurídica general en el marco de la solución de un caso concreto (p. 280 y s.), pues al principio solo hay un texto carente de normatividad y el "trabajador jurídico" le asigna un significado estructuralmente dependiente del uso en el caso.
} 


\section{LA SELECCIÓN DE LA PREMISA MAYOR}

El trabajo previo con la premisa mayor consiste en una actividad de búsqueda y selección de un precepto jurídico válido que luego será objeto de interpretación para resultar aplicable en el caso concreto. Esta búsqueda, por cierto, no se lleva a cabo de manera solipsista, sino que frente a la controversia entre las partes acerca de cuál precepto ha de fungir como premisa mayor de la decisión. Es en el contexto de esta discusión donde se forja la precomprensión del juez acerca de la regla jurídica pertinente al caso. Al cabo de este proceso de búsqueda, este selecciona el precepto jurídico que funge como premisa mayor. Mas, como lo precisa Tarello, no se elige simplemente un precepto, sino que más bien se recorta un segmento del discurso preceptivo "constituido por un enunciado o por más enunciados relacionados, que se adapte, según un significado que le es a tal efecto atribuido, al caso particular a cualificar según el derecho" ${ }^{54}$. Dicha selección ya supone una decisión del juez ${ }^{55}$. Pero esta decisión se encuentra sometida al menos a dos parámetros que constituyen límites a esta acción. El primero surge de la observación del carácter preceptivo del enunciado seleccionado. No se trata de cualquier texto ni de cualquier "documento", tampoco de cualquier "conjunto de vocablos", sino que de un precepto formulado con la pretensión de fundar derechos y obligaciones o de regular el comportamiento del ciudadano. En este sentido, el juez debe optar por el precepto jurídico que en el momento del conflicto aspiraba a servir de base para la solución de este o fungir como pauta de comportamiento $^{56}$. Este parámetro surge como consecuencia de la premisa de la normatividad del precepto jurídico que funge como modelo de regulación del comportamiento de los ciudadanos y, al mismo tiempo, de fundamento para la decisión judicial. El segundo parámetro surge de la restricción a la validez del precepto jurídico ${ }^{57}$. El juez debe optar por un precepto jurídico válido como premisa mayor de su decisión, para lo cual tiene que observar la diversa jerarquía de las fuentes, la vigencia temporal y espacial de la regla, resolver eventuales conflictos entre normas aplicables y, en su caso, identificar eventuales lagunas. Esta labor, desde luego, ya exige la interpretación del precepto, pero no todavía aquella conducente a la norma jurídica particular. Pues, la construcción de esta norma supone el caso concreto, esto es, el trabajo jurídico con la premisa fáctica.

\section{LA CONSTRUCCIÓN DE LA PREMISA MENOR}

La justificación interna de la decisión judicial supone la validez de la premisa fáctica. Como Caracciolo lo ha puesto de relieve, la operación de subsunción de un hecho bajo el supuesto descrito por una norma general ocurre en el medio del lenguaje, mas los hechos

\footnotetext{
54 Tarello (2018) p. 67.

55 Otra visión parece tener KelSEN (1960) pp. 424 y ss., de esta operación que define como un acto de comprobación ("Feststellung") de la norma jurídica general, aunque enseguida reconoce que como operación no es puramente declarativa, sino que tiene un carácter constitutivo.

56 Niegan dicha normatividad Müller y CHRISTENSEN (2013) p. 185 y s. ("el texto de la norma no es normativo").

57 Sobre el concepto de validez, véase ENGISCH (1971) pp. 71 y ss.: la validez supone que la instancia generadora de normas es reconocida en tanto pretende realizar una "idea de derecho" con su legislación; sobre la "idea de derecho" como "teoría del derecho correcto", esto es, de los principios y valores fundamentales a los cuales debe servir el derecho, pp. 196 y ss., 280 y ss.
} 
no integran el lenguaje, de modo que para poder hablar propiamente de la aplicación de normas a hechos se requiere que el juez afirme explícita o implícitamente la existencia temporal y espacial del suceso que describe y, además, que la proposición resultante sea verda$\operatorname{der}^{58}$. Asimismo, la decisión judicial como norma particular se sigue de la norma general solo si se incorpora una premisa que afirme la satisfacción en concreto de las condiciones de aplicación previstas en abstracto en el contenido de la norma ${ }^{59}$.

Cuando se usa la palabra "verdad" en este contexto, a veces se matiza su alcance señalando que se trata de una "verdad formal o jurídica", mas no de una "material", o aclarando que no está en juego una "verdad absoluta", sino solo una "relativa" ${ }^{60}$. Pero resulta algo pretencioso atribuirle a la ciencia del derecho autoridad para acuñar siquiera una clase propia de verdad como sería una "formal o jurídica". Ya la idea de que existen dos clases de "verdad empírica" no es inteligible, pues "la decisión de un juez no puede tornar verdadera una proposición factual falsa, ni falsa una verdadera (cualquiera que sea la naturaleza de la verdad)" ${ }^{\prime}$. Es decir, y como bien lo ha aclarado Taruffo, un enunciado es verdadero o no lo es, pero no puede ser más o menos verdadero. Lo que sí es graduable, explica, es el conocimiento de la verdad, pues este depende del contexto y del método usado, así como de la cantidad y calidad de la información disponible para fundarlo. En este sentido, el grado de confirmación que se puede atribuir a un enunciado sobre la base del conocimiento disponible sí puede variar según esos factores y ser mayor o menor ${ }^{62}$. Esta distinción es relevante para efectos de la construcción de la premisa menor como fundamento fáctico de la decisión judicial. Desde el punto de vista del contenido de la premisa fáctica, es necesario que la proposición sobre el hecho controvertido sea verdadera para justificar la decisión judicial como norma particular, esto es, para imponer la consecuencia jurídica prevista por la norma general. Y, como se recordó, la verdad o falsedad de una proposición es independiente del sujeto cognoscente. En cambio, el grado de confirmación del enunciado depende de la actividad desplegada por el sujeto para conocer la verdad, es decir, es la conclusión a la que se arriba en virtud de la información disponible y recolectada por el juzgador. En este otro sentido, la decisión judicial es observada como una acción del juez y la premisa fáctica como la construcción del relato acerca del hecho, premisa que se encuentra justificada si dicha construcción puede aceptarse bajo ciertos criterios de racionalidad. La implicancia de esta distinción es que no siempre la premisa fáctica que se considera racionalmente aceptable va a coincidir con la verdad de la proposición. Puede ocurrir, entonces, que la decisión como acción del juez se encuentre justificada, porque se apoya en reglas y criterios de valoración probatoria, pero la proposición sea falsa y, en estricto rigor, no proceda la aplicación de la consecuencia jurídica prevista por la norma. Y, al revés, puede suceder que la decisión como acción no se encuentre justificada, porque por ejemplo el juez no alcanza el grado de confirmación suficiente para tener la premisa por verdadera, pero la proposición

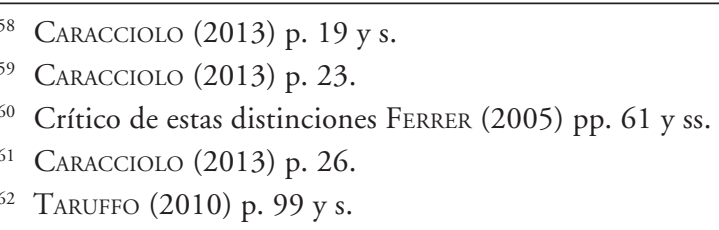


"casualmente" ser verdadera ${ }^{63}$. Lo cierto es que ambas dimensiones de la premisa fáctica son relevantes. Exigir de manera irrestricta la verdad de la proposición para la validez de la premisa fáctica como fundamento de la decisión sería algo ingenuo y poco realista. Pero reducir su validez a una mera decisión del juez, sin consideración de la verdad de la proposición, como advierte Caracciolo, implicaría "evaporar cualquier exigencia de corrección o justificación", de modo tal que ya no se podría distinguir entre una "sentencia arbitraria" y una "sentencia justificada" ${ }^{4}$.

Pues bien, la actividad de construcción de la premisa fáctica se encuentra sometida a una serie de reglas y criterios que ha sido estudiada por diversas teorías del proceso. Aquí es necesario subrayar que dicha premisa surge como producto de la actividad de un sujeto como es el juez. En este sentido, ya en 1965 Hruschka hizo ver con claridad que las proposiciones acuñadas por el juzgador tanto al elaborar y valorar el material probatorio como luego al formular las conclusiones fundadas en ellas son siempre respuestas a preguntas planteadas con anterioridad, obedecen, pues, a la "lógica de la pregunta y la respuesta" ${ }^{\text {". }}$. Al comienzo hay una pregunta que Hruschka denomina la pregunta básica y que el juzgador plantea desde una perspectiva impregnada a su vez por un interés práctico, no meramente teórico ${ }^{66}$. Dicha pregunta es además dinámica, pues su formulación puede implicar una modificación o ampliación del caso en base a la modificación previa del tema de prueba ${ }^{67}$. En este sentido, la pregunta implica la formulación de una hipótesis que luego tendrá que apoyarse en las pruebas y recibir un mayor o menor grado de confirmación.

Recientemente, Frisch ha dilucidado la estructura de la valoración probatoria sobre la base de la confirmación de una hipótesis fáctica y el análisis de eventuales hipótesis contrarias. La prueba necesaria de producir en relación con aquella supone que es compatible con el material probatorio elaborado y resulta confirmada por este. Tal confirmación exige no solo que las informaciones surgidas, por ejemplo, de la declaración de un testigo o de un perito sustenten total o parcialmente la hipótesis en cuanto a su contenido, sino además que se pueda partir de la verdad de dicha declaración. Para ello existe una serie de condiciones que debe cumplirse, por ejemplo, tratándose de un testigo supone que este haya podido observar el acontecimiento correctamente según las circunstancias y que posea la capacidad necesaria de recuerdo en la imagen experiencial del momento ${ }^{68}$. Es menester una reflexión en otro sentido cuando la producción de pruebas arroja informaciones que se contraponen a la hipótesis sometida a prueba. En tal evento, es necesario analizar el material probatorio que apoya una hipótesis diversa, por ejemplo, la circunstancia fáctica de una coartada, chequeando que efectivamente sea incoherente con la hipótesis objeto de prueba o verificando el cumplimiento de las condiciones para poder partir de la verdad de la información surgida de estas otras declaraciones. De este modo, la verdad de la hipótesis objeto de prueba

\footnotetext{
63 Ferrer (2005) pp. 96 y ss.

64 Caracciolo (2013) pp. 30 y ss., en discusión con Kelsen.

65 HruschKa (1965) pp. 20 y ss.: "proposiciones son siempre respuestas a preguntas decisivas. No existe ninguna proposición que no se refiera a una pregunta”.

66 HruschKa (1965) pp. 35 y ss.

67 HRUSCHKA (1965) pp. 59 y ss.

68 FRISCH (2013) p. 858 y s.
} 
supone excluir otra explicación del acontecimiento que sea diversa a ella ${ }^{69}$. Es decir, las preguntas que se formulan en el marco de la valoración de la prueba surgen de la lógica y la experiencia, pero también sus respuestas. Lógica y experiencia no solo le dan estructura a esta actividad, sino que también constituyen la substancia de las respuestas en la medida en que entregan las razones que fundan su resultado ${ }^{70}$. En este sentido, Taruffo ha precisado que la aplicación de la lógica y de las máximas de la experiencia en el proceso de valoración probatoria permite confirmar la hipótesis aplicando los criterios de inferencia. La confirmación surge de la conexión entre la afirmación que inicialmente tiene un carácter hipotético y las pruebas que confirman su "veracidad". Para la confirmación es menester que las pruebas sean entre sí convergentes, esto es, que la afirmación que se configura como hipótesis conclusiva de la inferencia no resulte excluida, falsificada o contradicha por hipótesis alternativas referidas al mismo hecho ${ }^{71}$. Asimismo, las inferencias que permiten dicha conexión entre pruebas e hipótesis fundan su validez y fiabilidad en los criterios que son usados a tal efecto. Aquellas son aptas para atribuir un grado considerable de fiabilidad a la respectiva conclusión cuando se basan en un fundamento cognoscitivo, de modo que esta es mayor o menor según la clase de conocimientos que le sirve de base, por ejemplo, si se trata de conocimientos científicos o solo de nociones de sentido común ${ }^{72}$.

La decisión final sobre los hechos, esto es, la narración construida por el juez resuelve la controversia atribuyendo a cada hipótesis el grado de confirmación que le corresponde sobre la base de las pruebas que se refieren a ella. En una escala gradual, este puede variar desde una confirmación fuerte, débil o ninguna de la hipótesis hasta la no confirmación de su falsedad, su confirmación débil o fuerte ${ }^{73}$. El grado de confirmación exigido para considerar verdadera la hipótesis previamente objeto de prueba depende del estándar probatorio que rige en el proceso respectivo. Se pueden distinguir al menos tres, esto es, desde el estándar de convicción que rige en el proceso penal hasta el de evidencia clara y convincente o solo de preponderancia de la evidencia que se postulan para el proceso civil ${ }^{74}$. Superado el estándar correspondiente, el paso final en la construcción de la premisa menor radica en la articulación de una narración sobre los hechos que se plasma en un texto. La narración que el juez ofrece es un conjunto ordenado de enunciados fácticos, cada uno de los cuales ha obtenido de las pruebas disponibles, racionalmente valoradas, una confirmación probatoria suficientemente fuerte ${ }^{75}$. Este texto corresponde a la motivación de la sentencia y en esta deben justificarse los enunciados que narran los hechos principales del caso en el sentido de explicitar las razones por las que es racional considerar que son verdaderos, es decir, se deben indicar las inferencias probatorias que atribuyen grados adecuados de confirmación a

\footnotetext{
69 FrisCH (2013) p. 860 y s., donde se refiere también a la prueba indiciaria.

70 Frisch (2013) p. 862 y s.

71 Taruffo (2010) p. 235 y s.

72 TARufFo (2010) p. 237 y s.

3 Taruffo (2010) p. 246 y ss.

74 Taruffo (2010) pp. 249 y ss.; en defensa del estándar de convicción Frisch (2013) pp. 863 y ss., 868 y ss.; sobre el estándar probatorio en el proceso civil LARROUCAU (2012) pp. 789 y ss.

75 TARuffo (2010) p. 253.
} 
esos enunciados ${ }^{76}$. Además, la motivación debe ser plena en el sentido de ofrecer las razones por las cuales a otros enunciados se les atribuye un grado débil de confirmación o ninguno ${ }^{77}$. Por último, ella debe ser congruente y coherente. De este modo, concluye Taruffo, si la motivación existe efectivamente, es además completa y coherente, entonces se puede decir que la narración de los hechos construida por el juez cuenta con una válida justificación racional, en la medida en que resulta confirmada por el análisis crítico de todas las pruebas disponibles; por ende, se puede decir que "enuncia la verdad"78.

\section{LA OPERACIÓN DE SUBSUNCIÓN Y LA CONSTRUCCIÓN DE LA NORMA JURÍdiCA PARTICULAR}

Ahora bien, y una vez que se ha concluido la actividad de construcción de la premisa fáctica, procede la subsunción del hecho así comprobado bajo el supuesto fáctico de la norma jurídica general. Engisch define esta operación en el sentido de la subordinación del caso fáctico bajo los elementos conceptuales del tipo o la asignación del caso concreto a la clase de casos descritos por el tipo legal ${ }^{79}$. Subsunción, dice, es la "equiparación del hecho representado como real con los hechos acuñados por el tipo legal" ${ }^{\circ}$. Sin embargo, Engisch reconoce que este paso supone no meramente el tipo sino su interpretación y que esta, al mismo tiempo, se encuentra referida al caso concreto, de modo que hay una permanente interacción, un "ir y venir de la mirada a la premisa mayor y al caso fáctico" ${ }^{21}$. La subsunción presupone la interpretación del precepto jurídico que funge como premisa mayor. Dicho de otra forma, la aplicación de una norma en el caso individual supone la operación de la interpretación del precepto legal.

No obstante, algunas veces el precepto jurídico que funge como premisa mayor se encuentra formulado en términos tales que la aplicación de la norma al caso individual se funda en una comprensión inmediata del precepto $^{82}$. Esto no implica que el juez prescinda de la interpretación, sino solo que en tal evento esta consiste en hacer explícitas las palabras usadas por el legislador. Es decir, el viejo aforismo "in claris non fit interpretatio" rige solo como una directiva metodológica en el sentido de "atenerse -allí donde fuere posible porque la letra de la ley no es obscura- a una interpretación declarativa" ${ }^{83}$. Pero, otras veces el precepto legal se encuentra construido en términos tales que impiden una comprensión inmediata y, por tanto, exigen continuar la actividad de la interpretación. Según Wróblews-

\footnotetext{
76 Taruffo (2010) p. 268 y s.

77 Taruffo (2010) p. 270 y s.

78 Taruffo (2010) p. 273 y s.

79 ENGisch (1960) pp. 23 y s., 25 y s. llegamos nunca”.

81 Engisch (1960) p. 14 y s., 32 y s.

82 Wróblewski (2013) p. 118 y s.

83 Tarello (2018) p. 70 y s., p. 175.
}

80 ENGISCH (1960) pp. 85 y ss., p. 89, p. 105: “comprobación fáctica es y permanece lógica, experiencial y conceptualmente observación elaborada, mientras que subsunción implica equiparación del caso a juzgar con los objetos acuñados por la ley"; una definición más plástica en Puppe (2011) p. 61: "una subsunción es la proposición de que algo real, una cosa, el atributo de una cosa, un hecho, satisface un concepto determinado. Pero esa realidad como tal nos está dada también solo en conceptos, a las cosas en sí y su conocimiento inmediato no 
ki, tal situación se presenta por la ambigüedad o la vaguedad de la "norma". Una expresión es ambigua cuando tiene más de un sentido, es decir, cuando se puede atribuir más de un significado al precepto. En cambio, la vaguedad de la "norma" deriva de la incerteza acerca de si el hecho queda o no abarcado por su extensión ${ }^{84}$. En tales casos, el juez aplica las directivas de interpretación a fin de explicar el sentido correcto del precepto, sentido que solo puede aclararse en su contexto, distinguiéndose al efecto entre el lingüístico, el sistémico y el funcional ${ }^{85}$.

En tales supuestos de ambigüedad o vaguedad del precepto legal se vuelve necesario continuar con la actividad de la interpretación. O como dice Aarnio: "la tarea es interpretación" $"$. El resultado de esta actividad es la atribución de un significado al precepto, momento en el cual surge la norma propiamente tal. En este sentido, dice Tarello: "El intérprete detecta, decide o propone el significado a atribuir a un documento, constituido por uno o más enunciados, cuyo significado no está en absoluto preconstituido a la actividad del intérprete, siendo más bien resultado de ella. Antes de la actividad del intérprete, del documento objeto de la interpretación se sabe solo que expresa una o más normas, no cuál es esta norma o cuáles sean estas normas: 'norma' significa simplemente el significado que ha sido dado, se decide dar o se propone dar, a un documento que se considera, sobre la base de indicios formales, exprese alguna directiva de acción" ${ }^{87}$. Cuando esta actividad es emprendida por el juez, esta siempre se lleva a cabo en relación con el caso individual sometido a su conocimiento y juicio -art. 3 inciso 2 del Código Civil (CC). Y, por ende, dicha actividad se realiza sobre el trasfondo de la "disputa semántica" entre las partes acerca del precepto jurídico que funge como premisa mayor, esto es, sobre el significado que cabe atribuirle al precepto. De todas las posibilidades de lectura del texto legislativo, es menester fijar una como definitiva ${ }^{88}$. Por consiguiente, la norma que surge como resultado de la atribución de significado al precepto luego de esa disputa es la norma jurídica particular.

Tal norma como resultado supone una decisión del juez, en el sentido de que pone término a la "disputa semántica". Como acto, esta decisión se encuentra sometida a una pretensión de corrección ${ }^{89}$. Su realización exige satisfacer ciertos criterios de corrección que se encuentran cristalizados en reglas y estándares de argumentación propios de una tradición jurídica determinada. Cuando se trata de la interpretación de un precepto legal, en nuestra tradición se han fijado reglas de interpretación en los artículos 19 y siguientes del $\mathrm{CC}^{90}$. En los términos de Wróblewski, estas reglas contienen directivas de interpretación de primer grado ${ }^{91}$. Son pautas que deben seguirse para alcanzar una justificación

\footnotetext{
84 WRÓBLEWSKI (2013) p. 120 y s.

85 WRÓBLEWSKI (2013) pp. 124 y ss.

86 AARnio (2016) p. 164.

87 Tarello (2018) p. 101 y s.; también GUASTini (2016) pp. 50 y ss.; ya Kelsen (1960) pp. 26 y ss., se refiere al sentido ("Sinn") subjetivo y objetivo del acto de voluntad.

88 Müller y Christensen (2013) p. 198.

89 Alexy (1983) p. 263, como parte del "discurso práctico".

90 Una revisión crítica del estado de la discusión sobre estas reglas ofrece QuiNTANA (2011) pp. 109 y ss.

91 WróbleWsKi (2013) pp. 128 y s.
} 
óptima de la decisión jurídica ${ }^{92}$. Así, las reglas del art. 19 inciso 1 así como de los artículos 20 y 21 orientan la interpretación a las palabras usadas por el legislador ${ }^{93}$. Dirigen esta actividad en orden a una indagación "puramente semántica" del precepto o a la explicación del sentido en su contexto lingüístico. Luego, la regla del art. 22 CC recoge el así llamado "elemento lógico" y orienta la interpretación al contexto sistémico, esto es, reconoce así la "interpretación sistemática" 94 . Y si la máxima latina "in claris non fit interpretatio" no es más que una directiva metodológica, entonces la regla del art. 19 inciso 2 CC puede concebirse como una directiva de sentido que orienta la interpretación al telos asignado por el legislador al precepto legal, reconociéndose así la "interpretación teleológica” 95 . De este modo, se pone de relieve la tríada de directivas de interpretación que sugiere un camino a seguir en la realización de esta actividad para atribuirle un significado al precepto jurídico: la interpretación semántica, sistemática y teleológica ${ }^{96}$. En esta labor interpretativa, el juez cuenta con el apoyo previo de la dogmática jurídica y de la jurisprudencia, en tanto conjunto de proposiciones acerca del derecho y elaboración conceptual del mismo ${ }^{97}$. La virtud de la dogmática radica en su insaciable pretensión de construcción de un sistema, mientras que lo peculiar de la jurisprudencia consiste en que, como dice Alexy, sus "proposiciones se usan no solo para compartir propuestas, sino que para la ejecución de acciones" 98 .

Si la aplicación de cada una de esas directivas conduce a la atribución de un significado diverso al precepto, según Wróblewski han de considerarse las directivas de interpretación de segundo grado, que guían al juez en la preferencia por una u otra directiva de sentido. La aplicación de estas reglas de segundo grado, a su vez, depende de lo que llama la "ideología estática o dinámica" acerca de la "norma”, en el sentido de que una concepción estática da primacía a las directivas lingüísticas y sistémicas, junto con entender la interpretación teleológica en base a la ratio legis del legislador histórico, mientras que una concepción dinámica resalta la directiva funcional obteniendo así mayor elasticidad en el sentido de la "norma" 99 . Ahora bien, y aún partiendo de una "ideología dinámica", cuando el juez se ve confrontado actualmente con el caso individual y la aplicación de las reglas de interpretación conduce a un resultado que considera en algún sentido contrario al principio de

\footnotetext{
92 AARNio (2016) pp. 164 y ss.; bajo la clasificación de Alexy entre reglas y principios, son "principios de la interpretación jurídica”.

93 Contemplan una "indagación puramente semántica" según Quintana (2011) pp. 150 y ss.

94 Desde una perspectiva hermenéutica QuinTANA (2011) pp. 158 y ss., distingue el significado, que se indaga en el ámbito de la literalidad, y el sentido que surge del contexto, los fines y la ratio; sobre los "elementos" lógico, gramatical, histórico y sistemático de la interpretación, con el disímil status del elemento teleológico en el Savigny temprano y tardío, ver Müller y Christensen (2013) p. 128 y s.; sobre el origen del elemento del telos en Ihering, HaVERKATE (1977) pp. 112 y ss.

95 Como aclara Aarnio (2016) p. 204 y s., dicho punto de vista interpretativo no es subjetivo, pues se reconstruye no solo en base a los "travaux préparatoires" sino que en conexión con el momento de la interpretación.

96 Wróblewski (2013) pp. 124 y ss.; Puppe (2011) pp. 77 y ss.; Zippelius (2012) pp. 41 y ss.; Larenz y CANARIS (1995) pp. 141 y ss.; por su parte AleXY (1983) p. 294 y s., suma el argumento histórico y el argumento comparativo, junto con reformular el teleológico.

97 Alexy (1983) pp. 307 y ss.; ver también Esser (1972) pp. 90 y ss.

98 AleXy (1983) p. 337.

99 Wróblewski (2013) pp. 128 y ss.
} 
justicia, todavía tiene que observar ciertos criterios antes de decidir el caso conforme a su propio "sentimiento de justicia". Esta es la situación en la cual se encuentra el juez cuando estima que el texto legislativo debe ser complementado o considera atribuirle un significado que va más allá del que surge de la aplicación de las directivas de interpretación de primer grado. En tal situación parece colocarse la regla del art. 24 CC, en la medida en que supone ya la aplicación de las "reglas de interpretación precedentes", incluida por ende la del art. 23. Pues bien, antes de resolver de ese modo el juez tiene que preguntarse si la corrección o integración buscada no es más que un propósito netamente político-jurídico o, por el contrario, puede emprenderse de lega lata, para lo cual debe ponderar entre los valores de la seguridad jurídica y el principio de justicia. Según Zippelius, si estima que puede proceder así, el juez igualmente debe tomar distancia de concepciones valorativas personalísimas y preguntarse qué decisión hermenéuticamente plausible se orienta mejor al "ethos jurídico" dominante en la comunidad ${ }^{100}$.

\section{EL CONTENIDO DE INJUSTO DE LA PREVARICACIÓN JUDICIAL}

Pues bien, luego de esta larga exploración en el modelo de una decisión judicial correcta es posible aproximarse al extremo opuesto del injusto de la prevaricación. Como se ha visto, una decisión correcta supone la validez de sus premisas y de su conclusión, esto es, que se encuentra justificada interna y externamente. La validez de las premisas, a su vez, deriva de una actividad de fundamentación de cada una de ellas realizada correctamente, es decir, conforme a las reglas y estándares de interpretación y argumentación propios de la tradición jurídica a la cual el juez pertenece. Como dice Engisch: "una decisión correcta es una decisión fundada conforme a método" ${ }^{101}$. En el extremo opuesto se ubica la realización de una actividad del mismo juez que funda lo injusto de la prevaricación.

En este sentido, y de la misma manera en que la corrección de la decisión judicial se funda en una actividad realizada a su vez correctamente, los tipos de prevaricación se estructuran sobre la base del comportamiento del juez. Así, el tipo del art. 223 N. 1 se refiere a la conducta de "fallar contra ley expresa y vigente", mientras que los tipos del art. 224 N. 1 y del art. 225 N. 1 CP aluden a la conducta de "dictar una sentencia manifiestamente injusta en una causa criminal o civil”. Para delimitar el contenido de injusto que surge de la realización de esta acción del juez es necesario perfilar antes la norma de comportamiento que subyace al tipo. Esta norma, a su vez, conecta con las directivas y reglas de conducta que el juez debe observar en el momento de decidir un caso civil o penal ${ }^{102}$. La configuración del tipo, entonces, supone la infracción a estas reglas básicas en la construcción de la decisión judicial.

\footnotetext{
100 Zippelius (1970) p. 243 y s.

101 Engisch (1963) p. 14; crítico Haverkate (1977) pp. 156 y ss.

102 Ya en este sentido Frisch (1983) pp. 366 y s., 399.
} 


\section{Delimitación de lo injusto En base al CRITERIO DE LA SOSTENIBILIDAD}

En esta labor de construcción de la decisión judicial, mediadora entre el texto legislativo y el caso individual, en esta actividad de creación de la norma jurídica particular, el juez es, a diferencia por ejemplo del testigo, sustituible, pues en principio "todo juez puede obtener el conocimiento jurídico que le permite decidir conforme al derecho real" ${ }^{103}$. En los casos claros, en que el precepto es fácilmente identificable, la comprobación del hecho inequívoca y la aplicación de la norma jurídica evidente, el juez ajusta su comportamiento de manera casi irreflexiva a las reglas básicas y estándares de la actividad judicial en términos tales que cualquier juez lo haría en su lugar. En cambio, en los casos difíciles por la ambigüedad del texto o la vaguedad de su lenguaje, de obscuridad o por la "contrariedad" valorativa que implicaría una aplicación inmediata de la norma jurídica, el juez tiene que detenerse a reflexionar en torno a cómo cualquier otro decidiría el caso y a trabajar con las premisas de su decisión. En tal situación, la decisión judicial como acción sigue sometida a una pretensión de corrección en el sentido de que su realización conduzca a premisas válidas de las cuales se derive correctamente la conclusión ${ }^{104}$. Mas para efectos del tipo de prevaricación, surge la pregunta por el baremo a partir del cual se puede juzgar la acción desplegada por el juez al decidir el caso. El baremo propuesto por la teoría objetiva aquí no sirve, pues esta presupone la existencia de un precepto legal inequívoco y una comprobación fáctica evidente. Y tampoco parece adecuado el baremo postulado por la teoría subjetiva, ya que en tal caso la configuración de la prevaricación quedaría supeditada enteramente a la "convicción personal" que el propio juez tiene acerca del "derecho correcto". De ahí la necesidad de buscar un baremo intersubjetivamente válido.

En estos supuestos, la configuración de lo injusto de la prevaricación supone traspasar el baremo de la sostenibilidad de la decisión judicial ${ }^{105}$. Es decir, solo una decisión judicial cuya fundamentación es insostenible puede fundar el injusto de la prevaricación. Este baremo plausible, empero, requiere de conceptualización y concreción para volverse operativo ${ }^{106}$. Pues bien, uno de los pocos juristas que ha ofrecido un concepto, quizás el único, es Jan Schuhr en un breve trabajo sobre la "sostenibilidad de una proposición jurídica" 107. De manera sorprendente, parte recurriendo al concepto de "cosa fungible" en el sentido del derecho de bienes, ya que la fungibilidad supone una relación de intercambiabilidad entre objetos en la medida en que pertenecen a una misma clase considerada equivalente. Como gran parte de la argumentación jurídica se desarrolla en el ámbito previo a la deducción lógica y allí el juzgador tiene que considerar diversos puntos de vista en colisión para fundar su proposición, estos puntos de apoyo pueden ser considerados aceptables sin tener que aprobarlos. Esta aceptabilidad de los puntos de vista en colisión vuelve las proposiciones equivalentes e intercambiables. Así entendido, advierte Schuhr, el concepto de sostenibilidad es aplicable solo en la parte no deductiva de la argumentación jurídica, en la medida en

103 Bemmann (1969) p. 69.

104 Coincidentes en ese punto de partida SAliger (2005) p. 142 y s.; SCHUHr (2008) p. 605.

105 Cfr. Kuhlen (2017) núm. marg. 42 y ss., 57 y ss.; crítico Hilgendorf (2009) núm. marg. 47 y ss.

106 Saliger (2005) pp. 143 y ss., recurre también a este baremo, pero sin ofrecer luego criterios de concreción.

107 Schuhr (2008) pp. 603 y ss. 
que supone un trabajo con los puntos de vista encontrados: "las conclusiones, en cambio, son siempre correctas o incorrectas, jamás sostenibles o insostenibles" ${ }^{108}$. En el ámbito de la aplicación del derecho, los criterios de aceptabilidad tienen que buscarse en la metodología jurídica y, por ende, la sostenibilidad de una proposición jurídica depende de que se pueda argumentar para fundarla de manera metódicamente intachable: "en la parte deductiva se exige el seguimiento de las leyes de la lógica, incluidas sus reglas de conclusión”. Los criterios de aceptabilidad, a su vez, se diferencian según se trate de la búsqueda de las normas del derecho vigente, que suponen la aplicación de reglas de delimitación y preferencia, o de la comprobación fáctica ${ }^{109}$. Pues bien, "la insostenibilidad de la decisión es un factor constitutivo del injusto de la prevaricación"110. Este supone una decisión judicial incorrecta porque su fundamentación es insostenible a la luz de las reglas básicas para la construcción de las premisas de la decisión. Se trata de una decisión cuya premisa normativa se apoya en puntos de vista interpretativos inaceptables por no ser fungibles entre sí, o cuya premisa fáctica se funda en una valoración de la prueba irracional por ilógica o no reconducible a las máximas de la experiencia. De este modo, es posible trazar una escala gradual que va desde una decisión judicial correcta en un extremo a una incorrecta pero sostenible entremedio -clase de decisión que no funda aún lo injusto de la prevaricación- hasta llegar a una decisión judicial incorrecta e insostenible fundante de tal injusto en el otro extremo.

Es muy interesante constatar que nuestra jurisprudencia se ha pronunciado en un sentido muy similar al propuesto en casos donde se resolvían querellas de capítulos. Así, en un fallo muy antiguo, que se pronuncia respecto de un capítulo en que se imputa a un juez la infracción de los artículos 148, 224 y 225 CP por haber mantenido personas -que habrían incurrido en el antiguo delito de vagancia- privadas de libertad más de 48 horas, la Corte de Valparaíso se refiere al art. 225 sobre negligencia inexcusable aclarando que "el mero error en la aplicación de las leyes no constituye responsabilidad sino cuando se incurre en él por negligencia o ignorancia que revisten esa condicion, es decir, toda vez que implica una injusticia de aquellas que no pueden esplicarse por una interpretacion razonable sino que, por el contrario, aparece de un modo claro i evidente, exenta de toda discusion lójica i racional la notoria contravencion del precepto de la lei"111. Casi un siglo después, la Corte Suprema se pronuncia en términos similares al conocer por vía de casación de los capítulos imputados a un juez civil bajo los artículos 224 N. 2 y 225 N. 1 CP por diversas infracciones a las reglas del procedimiento ejecutivo, sosteniendo que para la prevaricación no basta "la presunción general del conocimiento de la ley, sino que debe exigirse un conocimiento efectivo, no solo de su tenor, sino de su correcta interpretación; en otras palabras, 'el prevaricato no consiste en que una resolución sea contraria a la ley o en que el Juez aplique equivocadamente el derecho', sino que la incorrección jurídica de lo resuelto debe ir unida a la incorrección moral del juez, a la conciencia de este de estar aplicando una dis-

\footnotetext{
108 SCHUHR (2008) p. 604 y s.

109 Schuhr (2008) p. 606 y s.; atañen, entonces, a las precondiciones de la aceptabilidad racional del resultado de la interpretación, según AARnio (2016) p. 279 y s.

110 Schuhr (2008) p. 610.

111 Galleguillos con Silva (1898).
} 
posición en forma contraria a lo que su texto y sentido señalan"112. En un caso más reciente se trataba de una querella de capítulos presentada en contra de los integrantes de la Corte de Iquique con motivo de la resolución de un recurso de hecho que había sido presentado en contra de una sentencia del juez de garantía que a su vez había resuelto un incidente acogiendo la solicitud de exigencia previa de la querella de capítulos respecto de una jueza de policía local imputada por diversos delitos. Pues bien, en ese caso, la Corte de Arica, junto a otras consideraciones generales acerca de esa exigencia previa, sostiene respecto del art. 224 N. 1 que "dicha conducta exige negligencia o ignorancia inexcusables, vale decir, sea una falta de aplicación o descuido, o bien, un desconocimiento, que en ambos casos han de ser de tal intensidad, que sean indicativos de un comportamiento en el juez que suponga un manifiesto y absoluto desconocimiento del ordenamiento jurídico, de manera que la errónea aplicación del mismo no pueda verse amparada en las posibilidades de interpretación de la norma. Ello no puede ser de otra forma, ya que la negligencia o ignorancia inexcusables exigidas por el tipo penal deben diferenciarse del mero error interpretativo o aplicatorio de las leyes, y conforme al propio relato de los hechos que sustentan la querella, no se visualiza una actuación contraria a la Ley, que ponga de relieve un absoluto desconocimiento de la misma, excluyendo toda razonable interpretación" ${ }^{\prime 13}$.

Pues bien, si la diferencia entre una decisión incorrecta pero sostenible y una insostenible depende de la aplicación del método del derecho en la fundamentación de sus premisas, entonces la configuración del injusto de la prevaricación supone la infracción de las reglas básicas de interpretación y argumentación jurídica. Esta es precisamente la tesis que Rudolphi había sostenido en 1970, pensando en particular en los casos en que la ley contiene elementos indeterminados o confiere ámbitos de discrecionalidad: "Derecho es aquí la norma de decisión concreta obtenida de la ley por el juez en el caso individual correspondiente con los medios y métodos de la interpretación científico-jurídica, esto es, observando los deberes jurídicos que lo vinculan; prevaricación entonces es la desviación de esa norma de decisión necesariamente inequívoca" 114 . Esta tesis suele descalificarse por supuestamente concebir la prevaricación como mera "contravención al método" o reducir su contenido de injusto a la mera "infracción del deber" 115 . Esta crítica, empero, no se percata de que para llegar a la norma particular siempre hay que pasar por la interpretación del precepto legal correspondiente, aunque esta se agote en una indagación puramente semántica. De modo que lo único que garantiza una construcción de la norma jurídica particular sometida a los principios de igualdad y de seguridad jurídica es, en definitiva, la sujeción del juez a las mismas reglas de interpretación y estándares de argumentación que aplicaría cualquier otro juez en su lugar, esto es, que fluyen de la misma tradición jurídica a la cual pertenecen.

\footnotetext{
112 BANCO DE CONCEPCIÓN CON WETTLIN (1996).

113 Estrada CON Chiesa Y OtROS (2012).

114 Rudolphi (1970) p. 619.

115 Crítica, entre otros, de Saliger (2005) p. 145 y s.
} 


\section{LA SUBSUNCIÓN INCORRECTA COMO ELEMENTO DE INJUSTO RESULTATIVO}

Ahora bien, la infracción de esas reglas básicas de interpretación y argumentación es solo un factor constitutivo del injusto de la prevaricación, sin duda esencial. Dichas reglas básicas se infringen mediante la acción del juez. Otro elemento del injusto se configura con la decisión judicial misma como resultado de esa actividad previa desarrollada de manera incorrecta e insostenible. Partiendo del presupuesto de la existencia de un precepto jurídico a negar o confirmar, Binding sostenía que la prevaricación siempre se "funda en una subsunción conscientemente incorrecta del hecho bajo el derecho objetivo" ${ }^{116}$. Dada la correcta interpretación del precepto aplicable, esta subsunción incorrecta puede ocurrir por la comprobación falsa del hecho, verificación que frecuentemente deriva de una valoración conscientemente incorrecta del resultado probatorio. Asimismo, y no obstante la valoración correcta de este, dicha subsunción también puede tener lugar por la interpretación incorrecta del precepto jurídico pertinente. Y, finalmente, la subsunción incorrecta puede derivar de la subordinación del hecho bajo un precepto jurídico impertinente, que encierra siempre una interpretación incorrecta, o bajo un precepto inexistente, que el juez trata como un precepto jurídico, por ejemplo, uno inválido ${ }^{117}$. Binding veía en cada una de esas tres modalidades de la subsunción incorrecta la estructura común del injusto de la prevaricación judicial. Su concepción, sin embargo, se acuña en una época previa al desarrollo de la teoría del derecho a lo largo de todo el siglo 20.

En rigor, cada una de esas formas de la subsunción incorrecta no es más que el resultado incorrecto que surge como consecuencia de la actividad realizada previamente por el juez de modo insostenible. Así, la subsunción incorrecta del hecho comprobado bajo un precepto jurídico inválido resulta de una acción del juez que no observa las reglas sobre jerarquía y preferencia de normas, por ejemplo, en el caso de aplicar la consecuencia jurídica prevista por una ley derogada o abiertamente inválida. El juez selecciona una premisa mayor incorrecta en virtud de una acción realizada sin observar reglas básicas de argumentación jurídica. La subsunción incorrecta que deriva de la comprobación falsa del hecho es más bien el resultado incorrecto de la actividad realizada previamente por el juez contraviniendo las reglas más elementales en el proceso de valoración de la prueba y comprobación fáctica. El juez construye una premisa menor falsa como consecuencia de esta acción realizada de modo insostenible a la luz de esas reglas, por ejemplo, si infiere un enunciado fáctico en base a la declaración manifiestamente falsa prestada por un testigo o si, entre una hipótesis cuya verdad se funda en un grado fuerte de confirmación y la hipótesis contraria que no ha recibido ningún grado de confirmación o uno muy débil, opta derechamente por construir la narración sobre los hechos en base a esta última. Aquí es preciso considerar una asimetría existente entre un proceso civil y uno penal, pues ambos se encuentran sometidos a diversos estándares de prueba y reglas sobre carga probatoria que resuelven las situaciones de incertidumbre en uno u otro sentido ${ }^{118}$. En consecuencia, por ejemplo, un juez que considera que la hipótesis cuya verdad se discute no ha recibido el grado de confirmación suficiente

\footnotetext{
116 Binding (1905) t. 2, p. 559

117 Binding (1905) t. 2, p. 559.

118 TARUfFo (2010) p. 254 y ss.
} 
para superar el estándar y opta por la contraria que ha recibido un grado muy débil de confirmación, decide conforme a la regla del "in dubio pro reo"119. La subsunción incorrecta que resulta de la interpretación incorrecta de un precepto jurídico pertinente, como bien advierte Binding, conduce a un "pseudoprecepto", es decir, a una incorrecta norma jurídica particular. Esta surge como consecuencia de la actividad de interpretación y argumentación realizada con infracción a las reglas básicas y los estándares propios de una tradición jurídica determinada. Aquí también se presenta una asimetría entre un caso civil y uno penal. Pues, en un caso penal rige la prohibición de analogía solo "in malam partem”, de modo que el resultado consistente en la no subsunción del hecho bajo la norma por razones teleológicas no es necesariamente incorrecto ${ }^{120}$. Como sea, la subsunción incorrecta como resultado de una decisión judicial puede ser corregida o no por vía de casación en el fondo o de nulidad, mas no la realización de una acción del juez que infringe las reglas más básicas de interpretación y argumentación jurídica, acción que entonces merece ser contrarrestada mediante la aplicación de las normas de sanción de la prevaricación judicial.

\section{El aspecto SUbJETIVO}

El análisis de cualquier cuestión de orden subjetivo supone la configuración previa del contenido de injusto propio de la prevaricación judicial, esto es, que se ha dictado una decisión judicial incorrecta como consecuencia de una labor de construcción de sus premisas realizada de modo insostenible, es decir, con infracción de las reglas básicas de interpretación y argumentación jurídica. Lo anterior implica que, si la decisión judicial como resultado es incorrecta, pero la fundamentación de la premisa normativa o fáctica todavía se encuentra amparada por dichas reglas básicas, entonces la pregunta por el dolo ni siquiera se plantea ${ }^{121}$. Dolo, entonces, supone conocimiento de que la acción contraviene las reglas básicas de interpretación y argumentación jurídica, conocimiento que implica, a su vez, una decisión del juez por el resultado incorrecto. Por consiguiente, la prevaricación por ignorancia o negligencia radica en la dictación de una decisión judicial incorrecta fundada en premisas construidas de modo insostenible, pero donde la infracción de las reglas de interpretación o de argumentación jurídica se explica por el desconocimiento inexcusable de estas reglas o la poquísima diligencia del juez en su aplicación, respectivamente.

\section{CONCLUSIONES}

1. Los tipos de prevaricación judicial propia se encuentran construidos sobre la base de la vinculación del juez al derecho legislado en el momento de fallar una causa civil o penal. En este sentido, sus normas de comportamiento, cuyo destinatario es el propio juez, se fundan en la protección de un presupuesto básico del ejercicio correcto de la jurisdicción como es el principio de legalidad.

\footnotetext{
119 Clásico Frisch (1974) pp. 283 y ss., quien la concibe como una "regla de decisión" que forma parte de las "reglas sobre aplicación del derecho" y cuyo fundamento radica en el principio de justicia.

120 Puppe (2011) p. 109 y s.

121 En este sentido, FrISCH (1983) p. 366 y s.
} 
2. Una decisión judicial correcta, esto es, justificada interna y externamente, que resulta de la aplicación del derecho legislado en un caso concreto, civil o penal, gira en torno al eje de la subsunción de un hecho comprobado bajo un precepto legal interpretado. La corrección de la decisión judicial supone, entonces, un precepto legal válido que funge como premisa mayor, una proposición fáctica que enuncia la verdad y la subsunción del hecho así comprobado bajo la norma que resulta de la aplicación de las reglas básicas sobre interpretación jurídica.

3. Lo injusto de la prevaricación supone una decisión judicial incorrecta e insostenible, ya sea porque toma como premisa mayor un precepto inválido o porque la premisa fáctica se construye de manera irracional o porque la actividad de la interpretación contraviene las reglas básicas de este arte. El resultado propio de esta acción es una decisión judicial que incurre en una subsunción incorrecta.

\section{BIBLIOGRAFÍA CITADA}

Aarnio, Aulis (2016): Lo racional como razonable (Lima, Palestra).

Acosta, Juan Domingo (1983): “Aspectos generales de la prevaricación”, Revista Chilena de Derecho, vol. 10: pp. 103-124.

Alchourrón, Carlos y Bulygin, Eugenio (2015): Sistemas normativos (Buenos Aires, Editorial Astrea, 2a ed.).

AlEXY, Robert (1983): Theorie der juristischen Argumentation (Frankfurt a.M., Suhrkamp).

BaCigalupo, Enrique (2004): "Über die richterliche Rechtsbeugung”, en VV.AA, Festschrift für Hans-Joachim Rudolphi zum 70. Geburtstag (Neuwied, Wolters Kluver) pp. 381-390.

Bemmann, Günter (1969): "Zum Wesen der Rechtsbeugung”, Goldtammer's Archiv für Strafrecht: pp. 65-70.

BIERLING, Ernst Rudolf (1894): Juristische Prinzipienlehre (Freiburg/Leipzig, Mohr).

Binding, Karl (1905): Lehrbuch des gemeinen deutschen Strafrechts. Besonderer Teil (Leipzig, Verlag von Wilhelm Engelmann).

Caracciolo, Ricardo (2011): "Paradigmas de decisión judicial” (manuscrito): pp. 1-23.

Caracciolo, Ricardo (2013): "El problema de los hechos en la justificación de las sentencias”, Isonomía, núm. 38: pp. 13-34.

Carbonell, Flavia (2017): "Elementos para un modelo de decisión judicial correcta", Revista de estudios de la justicia. núm. 27: pp. 1-35.

Coloma, Rodrigo (2017): "Bases de un modelo conceptual para decidir hechos", Doxa, núm. 40: pp. 69-92.

ENGISCH, Karl (1960): Logische Studien zur Gesetzesanwendung (Heidelberg, Carl Winter Universitätsverlag, 2a ed.).

Engisch, Karl (1963): Wahrheit und Richtigkeit im juristischen Denken (München, Max Hueber).

EngISCH, Karl (1971): Auf der Suche nach der Gerechtigkeit (München, R. Piper \& Co. Verlag).

EsSER, Josef (1972): Vorverständnis und Methodenwahl in der Rechtsfindung (Frankfurt a.M., Fischer Athenäum).

FErrer, Jordi (2005): Prueba y verdad en el derecho (Madrid/Barcelona, Marcial Pons, 2a ed.). 
Frisch, Wolfgang (1974): “Zum Wesen des Grundsatzes 'in dubio pro reo”, en VV.AA, Festschrift für Heinrich Henkel zum 70. Geburtstag (Berlin/New York, De Gruyter): pp. 273-286.

FrISCH, Wolfgang (1983): Vorsatz und Risiko (Köln, Carl Heymanns Verlag).

FrISCH, Wolfgang (2013): "Freie Beweiswürdigung und Beweismaß”, en VV.AA, Festschrift für Rolf Stürner zum 70. Geburtstag, tomo 1 (Tübingen, Mohr) pp. 849-874.

Guastini, Riccardo (2016): La sintaxis del derecho (Madrid/Barcelona, Marcial Pons).

GuZmán Dalbora, José Luis (2008): Introducción a los delitos contra la administración de justicia (Managua, Instituto de estudio e investigación jurídica).

Hart, Herbert L.A. (2012): El concepto de derecho (Buenos Aires, AbeledoPerrot, $3^{\mathrm{a}}$ ed.).

Haverkate, Görg (1977): Gewissheitsverluste im juristischen Denken (Berlin, Duncker \& Humblot).

Hilgendorf, Eric (2009): “Rechtsbeugung \$339”, en VV.AA, Strafgesetzbuch. Leipziger Kommentar (Berlin, De Gruyter, 12a ed.).

HruschKa, Joachim (1965): Die Konstitution des Rechtsfalles (Berlin, Duncker \& Humblot).

Kelsen, Hans (1960): Reine Rechtslehre (Tübingen/Wien, Mohr Siebeck, 2a ed.).

KoHler, Josef (1904): "Über den Begriff der Rechtsbeugung", Deutsche Juristen-Zeitung, núm. 13: pp. 613-616.

Kuhlen, Lothar (2017): “Rechtsbeugung $\$ 339 ”$, en VV.AA., Strafgesetzbuch. NomosKommentar (Baden-Baden, Nomos, 5a ed.).

LAREnZ, Karl y CANaris, Wilhelm (1995): Methodenlehre der Rechtswissenschaft (Berlin/Heidelberg, Springer, $3^{\mathrm{a}}$ ed.).

Larroucau, Jorge (2012): "Hacia un estándar de prueba civil", Revista Chilena de Derecho, vol. 39: pp. 783-808.

Luhmann, Niklas (1993): Das Recht der Gesellschaft (Frankfurt a.M., Suhrkamp).

Müller, Friedrich y Christensen, Ralph (2013): Juristische Methodik (Berlin, Duncker \& Humblot, $11^{\mathrm{a}} \mathrm{ed}$.).

Ossandón, Magdalena y Rodríguez, Luis (2008): Delitos contra la función pública (Santiago, Editorial Jurídica, 2a ed.).

Puppe, Ingeborg (2011): Kleine Schule des juristischen Denkens (Göttingen, Vandenhoeck \& Ruprecht, 2a ed.).

QuintanA, Fernando (2011): Interpretación y argumentación jurídica (Santiago, Editorial Jurídica).

Rudolphi, Hans-Joachim (1970): “Zum Wesen der Rechtsbeugung”, Zeitschrift für die gesamte Strafrechtswissenschaft, tomo 82: pp. 610-632.

SAliger, Frank (2005): "Rechtsphilosophische Probleme der Rechtsbeugung", Archiv für Rechts- und Sozialphilosophie, separata núm. 104: pp. 138-154.

SchuHr, Jan (2008): “Zur Vertretbarkeit einer rechtlichen Aussage”, JuristenZeitung, núm. 12: pp. 603-611.

Tarello, Giovanni (2018): La interpretación de la ley (Lima, Palestra).

TARuffo, Michele (2010): Simplemente la verdad (Madrid/Barcelona, Marcial Pons).

Weinberger, Ota (1988): Norm und Institution (Wien, Manz'sche Verlags- und Universitätsbuchhandlung). 
Wilenmann, Javier (2011): "La administración de justicia como un bien jurídico", Revista de Derecho Pontificia Universidad Católica de Valparaíso, 1. sem.: pp. 531-573.

WróbleWsKI, Jerzy (2013): Sentido y hecho en el derecho (Lima, Grijley).

Zippelius, Reinhold (1970): "Rechtsnorm und richterliche Entscheidungsfreiheit", Juristen-Zeitung, núm. 18: pp. 241-245.

ZipPELIUS, Reinhold (2012): Juristische Methodenlehre (München, Beck, 11ª ed.).

\section{JURISPRUDENCIA CITADA}

GALleguillos CON SiLVA (1898): Corte de Apelaciones de Valparaíso, 22 de junio, Gaceta de los Tribunales, año LVIII, núm. 5,014, pp. 897-902.

BANCo de Concepción con Wettlin (1996): Corte Suprema, 31 de enero, Revista de Derecho y Jurisprudencia, tomo I (1996), II, sección cuarta, pp. 34-39.

Estrada con Chiesa y otros (2012): Corte de Apelaciones de Arica, 12 de marzo, Rol No 64-2012, en vLex, Id. 366521698. 